\title{
DESIGN OF T-SHAPED FRACTAL PATCH ANTENNA FOR WIRELESS APPLICATIONS
}

\author{
Manpreet Kaur ${ }^{1}$, A.P. Deepinder Singh ${ }^{2}$, Gagandeep Singh Gill ${ }^{3}$ \\ ${ }^{1}$ Student, M.Tech, Electronics and communication engineering, BFCET Bathinda, Punjab, India \\ ${ }^{2}$ Assistant professor, Electronics and communication engineering, BFCET Bathinda, Punjab, India \\ ${ }^{3}$ Student, M.Tech, Electronics and communication engineering, BFCET Bathinda, Punjab, India
}

\begin{abstract}
Since the evolution of the patch antennas, there is rapid growth observed in the applications of the patch antenna. There are number of advantages such as small size, ease of fabrication and installment, and a stable performance, so there are huge number of designs has been developed and presented by the researchers time to time. Taking an example of the mobile phone antennas, the antenna must have a small size and must be capable to resonate at multiple frequency bands. Reviewing about the various requirements of the antenna design for the wireless applications a novel multiple band fractal patch antenna has been designed. In this paper, a T-shaped patch antenna has been designed and discussed and fractal geometry has been applied to it in order to obtain self-similar characteristics. The dimensions of the Square Patch has been taken as $36 \times 36 \mathrm{~mm}$. Dimension of ground has been taken as been taken as $50 \times 50 \mathrm{~mm}$. The substrate material used for antenna design is FR-4 having dielectric constant 4.4. Antenna resonates at four operating bands $3.5 \mathrm{GHz}, 4.48 \mathrm{GHz}, 6.1 \mathrm{GHz}$ and $8.17 \mathrm{GHz}$. This antenna has return loss of $-16.76 \mathrm{~dB}$, $-16 \mathrm{~dB},-28.63 \mathrm{~dB}$ and $-15.03 \mathrm{~dB}$ with bandwidth of $432 \mathrm{MHz}, 332 \mathrm{MHz}, 295 \mathrm{MHz}$ and $364 \mathrm{MHz}$ at resonant frequencies. Further this antenna has impressive gain of $3.55 \mathrm{dBi}, 5.7 \mathrm{dBi}$ and $3.16 \mathrm{dBi}$ and $3.27 \mathrm{dBi}$ at corresponding frequencies. This antenna can be useful for Wi-Max, $4 G$ network, WLAN, Satellite \& RADAR communication applications.
\end{abstract}

Key Words: Wireless applications, WLAN, Fractal Microstrip Patch Antenna.

\section{INTRODUCTION}

Antenna is one of the largest components of the low profile wireless communication. In order to transmit and receive antenna information; modulation is done in which career wave is superimposed over modulating signal. At the required destination, the modulated signal was then received and the original information signal can be recovered by demodulation. A patch antenna is a narrowband antenna with large beam width. It is fabricated by etching the antenna element pattern in metal trace which is bonded to an insulating dielectric substrate such as a printed circuit board with a continuous metal layer bonded to the opposite side of the substrate known as a ground plane. Fractal geometry is used to reduce the size of patch antenna.

Fractal geometries have two common properties: space filling and self-similarity. It is found that by applying fractal geometry, self-repeating structures are obtained. Fractal geometries that have been used in this paper are Minkowski fractal geometry and self-similar shapes. By applying fractal geometry on patch, area of patch decreases, resonant length increases and number of frequency bands of antenna increases. Microstrip antenna finds applications from $1 \mathrm{GHz}$ to $12 \mathrm{GHz}$. Hence microstrip antenna can be designed for $\mathrm{L}$ band, $\mathrm{S}$ band, $\mathrm{C}$ band and $\mathrm{X}$ band applications.

\section{LITERATURE REVIEW}

Minkowski fractal reader antenna composed of three layers designed for handheld RFID reader systems. It operates at
$2.425 \mathrm{GHz}$ with a return loss of $-30.22 \mathrm{~dB}$ and a bandwidth of $100 \mathrm{MHz}$ [1].

A new E-shape fractal antenna for multi standard application is proposed. Fractal geometry is best suited for its self similarity and space filling characteristics. [2]

E-Shaped fractal patch antenna with DGS has been proposed. By using FR-4 epoxy as substrate antenna resonates at $3.7 \mathrm{GHz}, 6.7 \mathrm{GHz}, 7.9 \mathrm{GHz}$ and $8.7 \mathrm{GHz}$ respectively with bandwidth $120 \mathrm{MHz}, 495 \mathrm{MHz}, 225 \mathrm{MHz}$ and $315 \mathrm{MHz}$ at corresponding frequencies [3].

I shaped fractal patch antenna with three iterations have been applied one by one on square patch which results in fractal patch antenna which resonates at $4.7 \mathrm{GHz}, 6.5 \mathrm{GHz}$, $7.7 \mathrm{GHz}$ and $8.5 \mathrm{GHz}$ respectively with bandwidth of 150 $\mathrm{MHz}, 135 \mathrm{MHz}, 520 \mathrm{MHz}$ and $1.2 \mathrm{GHz}$ at corresponding frequencies. This antenna finds applications for defense and secure communication. [4]

H-shaped patch antenna by applying DGS in horizontal direction and vertical direction, characteristics of antenna are observed. Antenna resonated at $2.7 \mathrm{GHz}, 4.8 \mathrm{GHz}$ and $6.2 \mathrm{GHz}$ with return loss of $-17.66 \mathrm{~dB},-13.6 \mathrm{~dB}$ and -23.66 $\mathrm{dB}$. This antenna has gain of $6.05 \mathrm{dBi}, 5.6 \mathrm{dBi}$ and $3.66 \mathrm{dBi}$. [5] 


\section{ANTENNA DESIGN}

\subsection{Design Considerations for Fractal Antenna}

Fractal geometry is applied to antenna so as to obtain multiband characteristics. Dimensions of antenna depend on desired frequency of application. If antenna is designed for small frequencies, size would be large. Size of antenna also depends on dielectric substrate. If substrate has large dielectric constant, size would be small but efficiency and bandwidth decreases. A better approximation for the resonant length is:

$$
\mathrm{L}=0.49 \frac{20}{\sqrt{e r}}
$$

This formula includes a first order correction for the edge extension due to the fringing fields, with:

$\mathrm{L}=$ resonant length

$\lambda_{0}=$ wavelength in free space

$\epsilon_{\mathrm{r}}=$ dielectric constant of the PC board material

Other parameters that will influence the resonant frequency are as given below:

- Ground plane size

- Metal (copper) thickness

- Patch (impedance) width

Calculation of the Width (W): The width of the microstrip patch antenna is given by equation as:

$$
\mathrm{W}=\frac{c}{2 f_{0} \sqrt{\frac{\varepsilon_{\mathrm{r}}+1}{2}}}
$$

Where,

$\mathrm{W}=$ width of the patch antenna

$\mathrm{c}=$ speed of light in free space

$\mathrm{f}_{\mathrm{o}}=$ centre frequency of the designed antenna.

$\epsilon_{\mathrm{r}}=$ dielectric constant of the PC board material

So, by increasing the dielectric constant the patch dimensions will be smaller.

\subsection{Design of Fractal Microstrip Patch Antenna:}

Design of T-shaped fractal microstrip patch antenna has been obtained by applying fractal geometry.

Table-1: Dimensions of antenna.

\begin{tabular}{|c|c|}
\hline Variable & Value \\
\hline Dimension of square patch & $36 \mathrm{~mm}$ \\
\hline Dimension of square ground & $50 \mathrm{~mm}$ \\
\hline Substrate used & FR-4 \\
\hline Feeding Technique & Coaxial Feed \\
\hline Fractal geometry algorithm & Minkowski Geometry \\
\hline $\begin{array}{c}\text { Dimension of first iteration } \\
\text { iteration }\end{array}$ & $12 * 18$ \\
\hline \begin{tabular}{c} 
Dimension of second \\
\hline
\end{tabular} & $4 * 9$ \\
\hline
\end{tabular}

First of all, square of $36 \mathrm{~mm}$ is divided into half, and $36 \mathrm{~mm}$ is divided into 3 parts. Hence two a rectangle of $18 \mathrm{~mm}$ in length and $12 \mathrm{~mm}$ in width are removed to form T-shaped patch as shown in Figure 2.

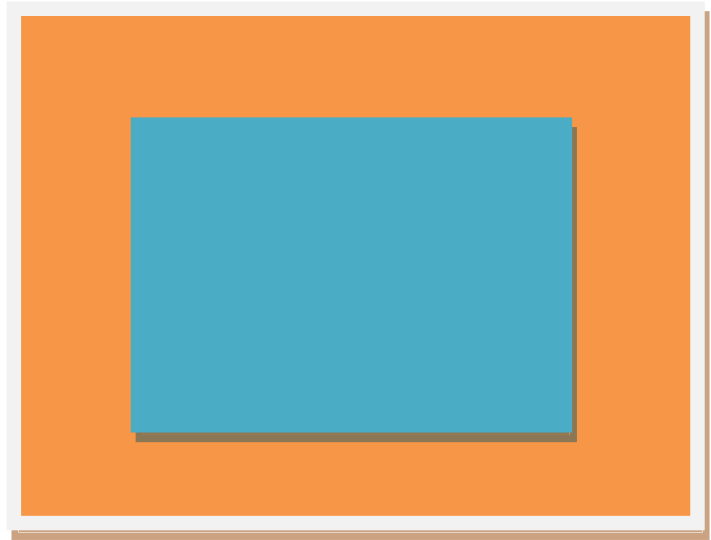

Fig-1: Basic Square Geometry

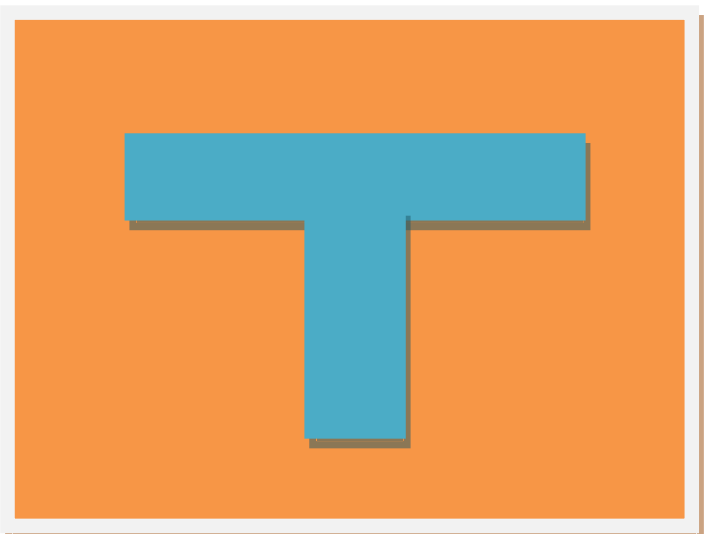

Fig-2: First Iteration

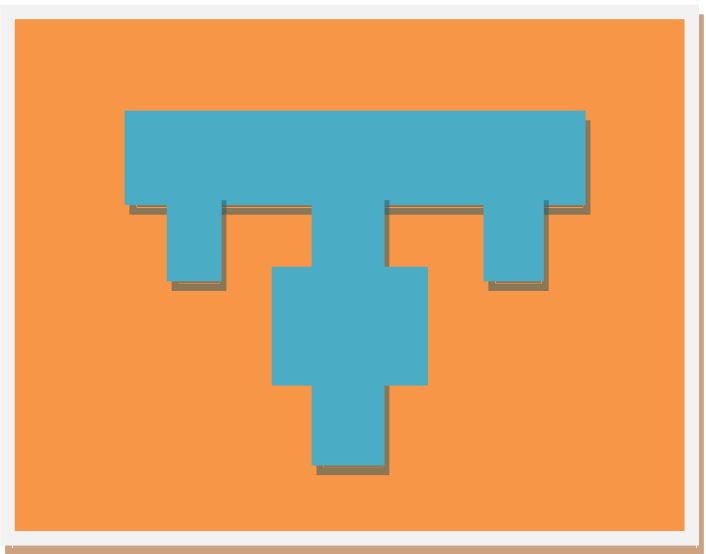

Fig- 3: Second Iteration

Now four rectangles of dimension $12 \times 18 \mathrm{~mm}$ are formed hence $\mathrm{x}$ axis is divided into three parts and $\mathrm{y}$ into two and two rectangles of dimension 4 by $9 \mathrm{~mm}$ are removed from rectangle to form self similar structure as shown in Figure 3. Geometry as shown in Figure 1, 2, and 3 is self similar structures geometry. Beyond a certain level of iteration, it is difficult to fabricate antenna as cuts become small which cause difficult for antenna to make practically. 


\section{RESULTS \& DISCUSSION}

T-Shaped Fractal Patch Antenna: In this section, simulation results of different iterations of fractal geometry are compared. $\mathrm{T}$ shape fractal antenna is made by cutting slots as shown in Figure 1, 2, and 3. These cause self-similar T-shaped structure. Return loss vs. frequency for various iteration of T-shaped fractal geometry are_shown in Figure 4.

Base antenna $-1^{\text {st }}$ Iteration $-2^{\text {nd }}$ Iteration

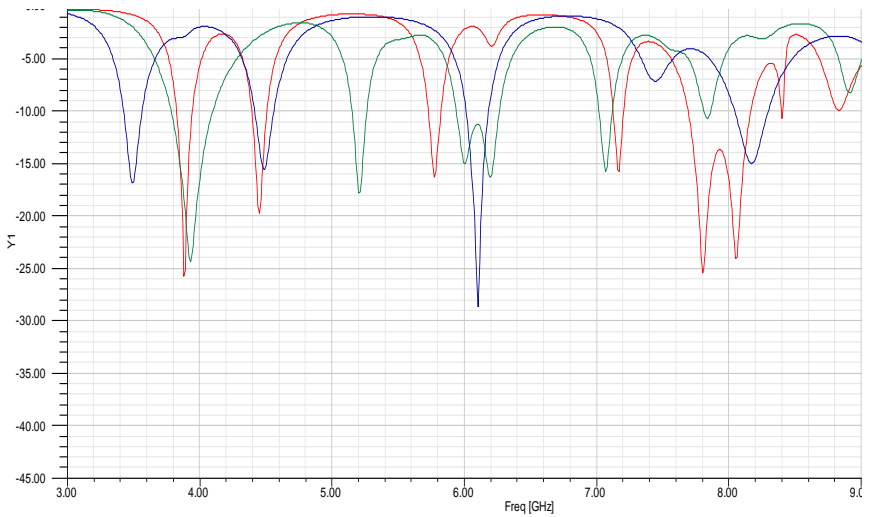

Fig- 4: Return Loss vs. Frequency for Different Fractal Iterations of T-shaped FMPA.

From Figure 4 it is found that characteristics of antenna increases as number of iterations increases, initially square antenna resonates at $3.88 \mathrm{GHz}, 5.47 \mathrm{GHz}$ and $7.8 \mathrm{GHz}$ with return loss of $-26 \mathrm{~dB},-17 \mathrm{~dB}$ and $-25 \mathrm{~dB}$ and bandwidth of $283 \mathrm{MHz}, 136 \mathrm{MHz}$ and $590 \mathrm{MHz}$. since characteristics of antenna at zeroth iteration are not good so fractal geometry has been applied to improve characteristics. Two slots are cut as shown in Figure 2. This antenna resonates at four bands at $3.94 \mathrm{GHz}, 5.2 \mathrm{GHz}, 6.2 \mathrm{GHz}$ and $7.06 \mathrm{GHz}$ with return loss of $-24 \mathrm{~dB},-18 \mathrm{~dB},-16 \mathrm{~dB},-16 \mathrm{~dB}$. This antenna has bandwidth of $354 \mathrm{MHz}, 211 \mathrm{MHz}, 516 \mathrm{MHz}$ and 295 $\mathrm{MHz}$ at resonant frequency. As results obtained are good but resonant frequency bands are having more return loss hence second iteration of fractal geometry is applied. When second iteration of fractal geometry is applied as shown in figure 3, antenna resonates at five bands with return loss of 3.54 $\mathrm{GHz}, 4.48 \mathrm{GHz}, 6.1 \mathrm{GHz}$ and $8.17 \mathrm{GHz}$. This antenna has return loss of $-16.76 \mathrm{~dB},-16 \mathrm{~dB},-28.63 \mathrm{~dB}$ and $-15.03 \mathrm{~dB}$ with bandwidth of $432 \mathrm{MHz}, 332 \mathrm{MHz}, 295 \mathrm{MHz}$ and 364 $\mathrm{MHz}$ at resonant frequencies. Further radiation patterns at $3.54 \mathrm{GHz}, 4.48 \mathrm{GHz}, 6.1 \mathrm{GHz}$ and $8.17 \mathrm{GHz}$ has been shown in figure $5,6,7,8$. When first iteration of fractal geometry has been applied, effective length of patch increases which result better antenna characteristics.

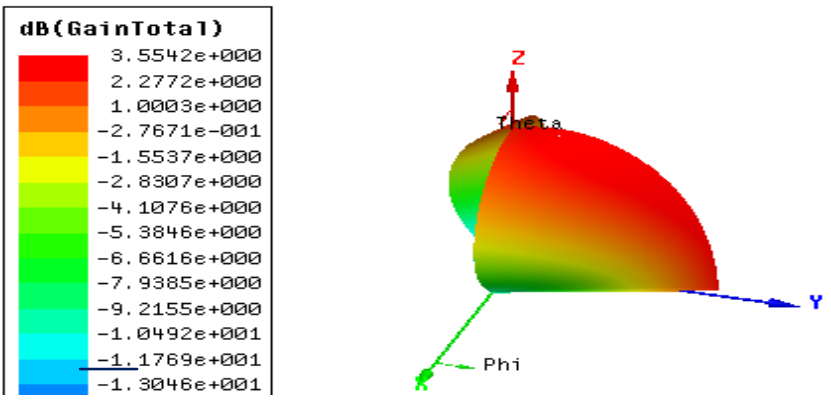

Fig - 5: Gain of T- shaped FMPA at $3.51 \mathrm{GHz}$
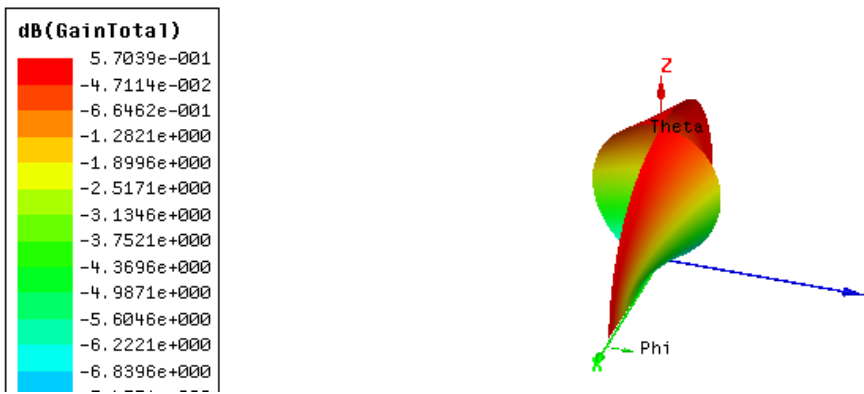

Fig - 6: Gain of T- shaped FMPA at $4.5 \mathrm{GHz}$
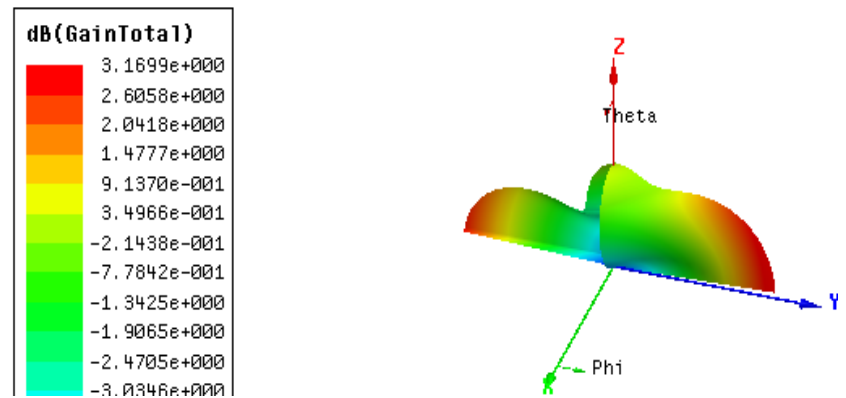

Fig - 7: Gain of T- shaped FMPA at $6.1 \mathrm{GHz}$
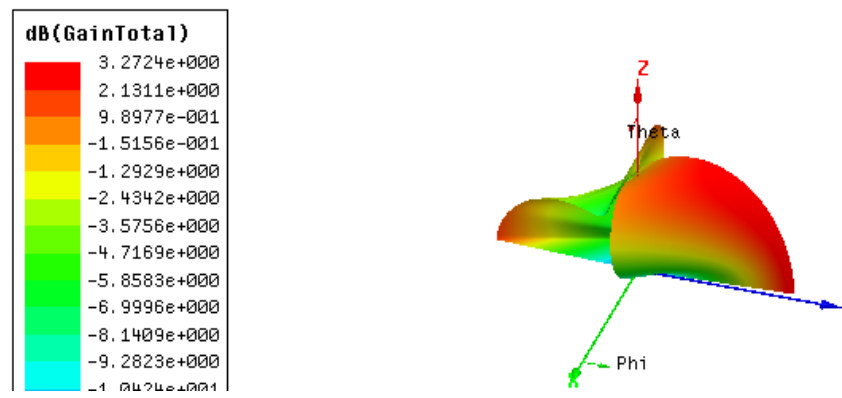

Fig - 8: Gain of T- shaped FMPA at $8.18 \mathrm{GHz}$

When second iteration is applied, number of fractal cuts increases which caused effective length to increase more and more, hence T-shaped fractal antenna in second iteration as shown in figure 3 has good characteristics in terms of return loss, gain and bandwidth. This radiation pattern shows that antenna is having maximum energy corresponds to that in particular direction. There are different radiation patterns like fan based, pencil based radiation pattern. 
Table - 2: Comparison Results of Different Iterations of T shaped FMPA.

\begin{tabular}{|c|c|c|c|c|c|}
\hline $\begin{array}{c}\text { No of } \\
\text { iteration }\end{array}$ & $\begin{array}{c}\text { Resonant } \\
\text { Frequency } \\
(\text { GHz) }\end{array}$ & $\begin{array}{c}\text { Retur } \\
\text { n Loss } \\
\text { (dB) }\end{array}$ & VSWR & $\begin{array}{l}\text { Gain } \\
\text { (dbi) }\end{array}$ & $\begin{array}{l}\text { Band } \\
\text { width } \\
\text { (MHz) } \\
\end{array}$ \\
\hline & 3.88 & -26 & 1.1 & 4.23 & 283 \\
\hline & 5.47 & -17 & 1.3 & 5.35 & 138 \\
\hline & 7.8 & -25 & 1.1 & 4.88 & 590 \\
\hline \multirow{4}{*}{$\begin{array}{c}\text { 1st } \\
\text { iteration }\end{array}$} & 3.94 & -24 & 1.12 & 2.39 & 364 \\
\hline & 5.2 & -18 & 1.2 & 3.9 & 211 \\
\hline & 6.2 & -16 & 1.3 & 3 & 516 \\
\hline & 7.06 & -16 & 1.3 & 5.23 & 141 \\
\hline \multirow{4}{*}{$\begin{array}{c}2^{\text {nd }} \\
\text { iteration }\end{array}$} & 3.5 & -16.76 & 1.33 & 3.55 & 432 \\
\hline & 4.48 & -16 & 1.39 & 5.7 & 332 \\
\hline & 6.1 & -28.63 & 1.07 & 3.16 & 295 \\
\hline & 8.17 & -15.03 & 1.43 & 3.27 & 364 \\
\hline
\end{tabular}

It is found from results that as dimension of antenna increases, result become better. Further it is also found that as one move from first to third iteration, number of bands and bandwidth increases. Voltage standing wave ratio is measure of reflection occur. When any incident wave travel from input side then at impedance terminal, because of improper matching, waves get reflected hence maxima's and minima's are formed. VSWR is ratio of voltage maxima to voltage minima and must be greater than one. This antenna has VSWR of $1.33,1.39,1.07$ and 1.43 at $3.54 \mathrm{GHz}, 4.48$ $\mathrm{GHz}, 6.1 \mathrm{GHz}$ and $8.17 \mathrm{GHz}$ at corresponding frequencies.

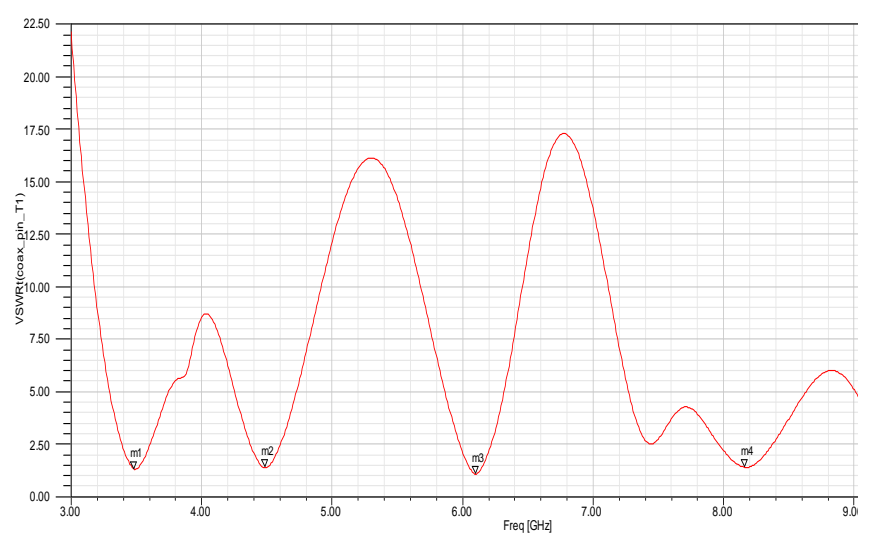

Fig - 9: VSWR of $2^{\text {nd }}$ iteration of T shaped FMPA.

One of important parameter is smith chart. By using smith chart one can have obtained reflection coefficient, maxima location, impedance matching and many other things. Figure 10 shows smith chart of proposed antenna.

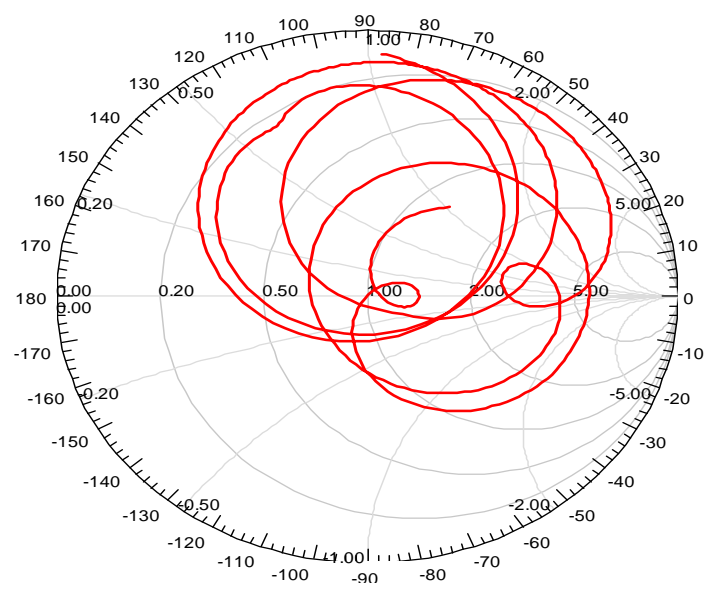

Fig- 10: Smith Chart of Proposed Antenna

\section{CONCLUSION}

It is found that by making use of fractal geometry, the characteristics of antenna improve to a great extent. In this paper, T-shaped Patch antenna has been designed and fractal geometry has been applied to it in order to obtain selfsimilar characteristics. Patch length has been taken as square of length $36 \mathrm{~mm}$. Dimension of ground has been taken as 50 $\mathrm{mm}$. The substrate used in this paper is FR-4. This antenna can be useful for Wi-Max and WLAN, Satellite and RADAR applications.

\section{REFRENCES}

[1]. Lei Cao, Shu Yan and Hanhua Yang " Study and Design of a Modified Fractal Antenna for RFID Applications" ISECS International Colloquium on Computing, Communication, Control, and Management, IEEE (2003).

[2].Qi Luo, H.M.Salgado, and J. R.Pereira "Printed Fractal Monopole Antenna Array for WLAN” IEEE (2013).

[3].A. Ismahayati, P.J Soh, R.Hadibah,G.A.E Vandenbosch "Design and Analysis of a Multiband Koch Fractal Monopole Antenna" IEEE international RF and Microwave references (RFM) 2011.

[4].H. Nornikman, B. H. Ahmad, M. Z. A. Abd Aziz, A. R. Othman, M. A. Azlishah "Design Minkowski Shaped Patch Antenna with Rectangular Parasitic Patch Elements for 5.8 GHz Applications" IEEE (2013.2011),12 $2^{\text {th }}-14^{\text {th }}$ December 2011,Malaysia.

[5].Devesh Kumar, Manish Sharma, Sakshi Bansal "Novel Design of Key-Shaped Fractal Antenna for UWB Applications" Sixth International Conference on Computational Intelligence and Communication Networks 2014.

6. Md. Mamun Hossain, Md. Abdul Wahed, M. A. Motin "Design and Simulation of a Dual Frequency E-Shaped Microstrip Patch Antenna for Wireless Communication" The 9th International Forum on Strategic Technology (IFOST), October 21-23, 2014, Cox’s Bazar, Bangladesh. 


\section{BIOGRAPHIES}

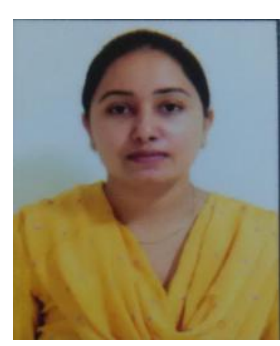

Manpreet Kaur is pursuing M.Tech from BFCET Bathinda, Punjab. She has done B.Tech from Punjab Technical University, Jalandhar in 2013. She Published one research paper in international journal. Her fields of interest are Microstrip patch antenna, fractal geometry, Reconfigurable antennas.

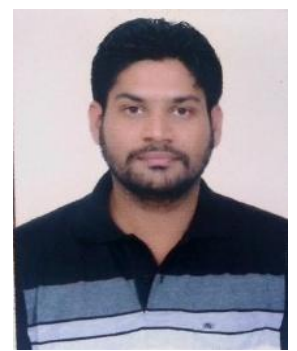

Deepinder Singh is working as Asst. Prof. in BFCET , Bathinda (Punjab). He has completed his M.Tech from Punjabi University Patiala, Punjab in 2012. He has published many research papers in international journals. His fields of interest are Microstrip patch antenna, and OCDMA.

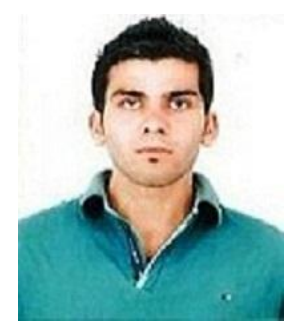

Gagandeep Singh Gill is a student pursuing M.Tech from BFCET, Bathnida (Punjab). He has done his B.Tech from Punjab Technical University Jalandhar in 2012. His areas of interest are patch antenna, inverted $\mathrm{F}$ antennas and fractal geometries 